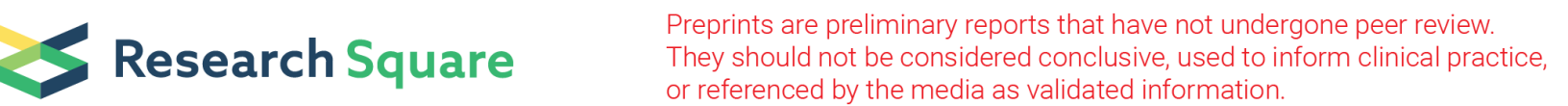

\section{The efficacy and safety of intrathecal bupivacaine alone versus bupivacaine combined with magnesium sulfate in adults using spinal anesthesia: a meta-analysis of randomized controlled trials}

\author{
Mi-Zhou Wang \\ Qingdao Municipal Hospital Group \\ Rui Dong \\ Qingdao Municipal Hospital Group \\ Li-Na Jia \\ Qingdao Municipal Hospital Group \\ Deng-Bin Ai \\ Qingdao Municipal Center for Disease Control and Prevention \\ Jian-Hua Zhang (D972777920@qq.com ) \\ Qingdao Municipal Hospital Group
}

Research article

Keywords: Magnesium sulfate, Postoperative analgesia, Spinal anesthesia, Bupivacaine

Posted Date: January 20th, 2020

DOI: https://doi.org/10.21203/rs.2.21367/v1

License: (c) (i) This work is licensed under a Creative Commons Attribution 4.0 International License.

Read Full License 


\section{Abstract}

Background: Several studies have investigated the effects of intrathecal magnesium sulfate as an adjuvant for bupivacaine; however, their conclusions are inconsistent. Therefore, it is necessary to conduct a meta-analysis on this topic.

Methods We searched Pubmed, EMBASE (OvidSP) and Cochrane Central Register of Controlled Trials (CENTRAL) for randomized controlled trials (RCTs) comparing the effect of intrathecal bupivacaine combined with magnesium sulfate versus bupivacaine alone in adults using spinal anesthesia.

Results Eighteen studies that met our inclusion criteria were included in our analysis. We found that the addition of intrathecal magnesium sulfate to bupivacaine provided a longer duration of analgesia (SMD $0.99 ; 95 \% \mathrm{Cl}[0.45,1.52], \mathrm{P}=0.0003, \mathrm{I} 2=93 \%)$, prolonged the duration of sensory block (MD=106.69; $95 \%$ $\mathrm{Cl}, 60.93-152.45 ; \mathrm{P}<0.00001)$, delayed the onset of sensory block (SMD 1.20; 95\% $\mathrm{Cl}[0.65,1.75], \mathrm{P}=$ $<0.0001, \mathrm{I} 2=91 \%$ ) and motor block (SMD 1.46; $95 \% \mathrm{Cl}[0.23,2.69], \mathrm{P}=0.02, \mathrm{I} 2=96 \%$ ), decreased the requirement for rescue analgesia (SMD $-0.81 ; 95 \% \mathrm{Cl}[-1.06,-0.56], \mathrm{P}<0.00001,12=11 \%$ ). For duration of motor block, and incidence of postoperative adverse events (such as nausea and vomiting, hypotension, bradycardia, pruritus, shivering and neurological deficit), no statistically differences were observed between the 2 groups.

Conclusions Our meta-analysis demonstrated that intrathecal magnesium sulfate combined with bupivacaine prolongs the dusration of analgesia, without an impact on the adverse events. However, the quality of evidence was very low when using GRADE to assess it. Given adverse effects before use, more high-quality trials with large samples are required before magnesium sulfate is routinely used as a intrathecal adjunct.

\section{Background}

Evidence indicates that more than $80 \%$ of patients experience acute postoperative pain and approximately $75 \%$ of those report pain of moderate, severe or extreme severity $[1,2]$. Inadequate pain management after surgery is associated with the risk of postoperative complications, delayed functional recovery, lower health-related quality of life, and at risk for developing persistent postsurgical pain [3]. Spinal anesthesia is considered the anesthetic technique of choice for lower abdominal, lower limb surgery and cesarean section, with the limitation of relatively short duration of the analgesia. Many adjuvant of intrathecal bupivacaine aims to prolong the duration of postoperative analgesia, but conventional analgesics, such as opioids, a2-adrenergic agonists, midazolam, et al. may be associated with increased incidence of nausea and vomiting, bradycardia, hypotension, and pruritus [4-6].

Previous studies have demonstrated that N-methyl-D-aspartate (NMDA) receptors areinvolved in the induction and maintenance of the central sensitization and windup is reduced by pretreatment with NMDA antagonists [7]. Magnesium ion blocks inward current flow through ion channels (such as $\mathrm{K}^{+}$and $\mathrm{Ca}^{2+}$ ) linked to N-methyl-D-aspartate (NMDA) receptors, playing as a non-competitive NMDA receptor 
antagonist [8]. In addition, several studies have investigated the effects of magnesium sulfate as an adjuvant in spinal analgesia and anesthesia; however, their conclusions are inconsistent. Therefore, it is necessary to conduct a meta-analysis to evaluate the effects and safety of intrathecal magnesium sulfate combined with bupivacaine in providing postoperative analgesia.

\section{Materials And Methods}

The review was adhered to the Preferred Reporting Items for Systematic Reviews and Meta-Analyses (PRISMA) statement [9], and we used GRADE to assess the overall quality of evidence [10].

\subsection{Eligibility criteria}

We included randomized controlled trials (RCTs) that compared intrathecal magnesium sulfate combined with bupivacaine (intervention group) versus bupivacaine alone (control group) in adults undergoing surgical procedures under spinal anesthesia. Trials reporting analgesia after epidural or venous administration of magnesium were excluded. Trials that evaluated the effect of intrthecal magnesium sulfate combined with bupivacaine and other analgesics (e.g. fentanyl, morphine) were excluded. Included studies had to report data at least on primary outcome or secondery outcomes (primary outcome: duraton of analgesia, defined as the time to the first complaint of pain or request for analgesics; secondary outcomes: onset of sensory and motor block, duration of sensory and motor block, requirement for rescue analgesia, and postoperative adverse events such as the incidence of postoperative nausea and vomiting (PONV), hypotension, bradycardia, pruritus, shivering and neurological deficit). No minimum sample size was required for inclusion in the meta-analysis.

\subsection{Search strategy and study selection}

We systematicly searched EMBASE, the Cochrane Central Registry of Controlled Trials (CENTRAL), and Pubmed databases from their inception until 29 December 2019. Search terms was a combination of subject words and free words connected by logical operators such as "and", "or", and "not". Keywords for search were: intrathecal, subarachnoid, neuraxial, spinal, magnesium, MgSO4, magnesium sulfate, magnesium sulphate. Language restriction was English. We also manually searched the references of the included studies and related reviews for additional studies. Two researchers (Wang and Dong) independently screened the studies based on their titles and abstracts. The full text of these articles were then screened for compliance with the inclusion criteria. Any disagreement between the two researchers was resolved by discussion and consensus with a third investigator (Jia).

\subsection{Data extraction and bias risk assessment of the included studies}


Two authors (Wang and Dong) independently performed data extraction using a predesigned data extraction table. If PONV was reported as two separate items in the included studies, we included only vomiting in the analysis. If means and standard deviation (SD) were not reported in the study, we used medians, interquartile ranges (IQRs), or ranges to estimate them according to the methods advocated by Wan et al [11]. Two review authors (Wang and Dong) independently evaluated the risk of bias of the included studies applying the Cochrane Collaboration's tool [12]. Studies at high or unclear risk of bias in one or more domains for random sequence generation, allocation concealment, participant and personnel blinding, outcome assessment blinding, and incomplete outcome data were rated to be of 'low' quality, otherwise they were considered as 'high' quality. Any disagreement between the two researchers was resolved by discussion and consensus with a third investigator (Jia).

\subsection{Statistical analysis}

Statistical analyses were conducted using Revman 5.0. Continuous variables (e.g. the duraton of analgesia, onset of sensory and motor block, duration of sensory and motor block, requirement for rescue analgesia) were analyzed by standardized mean difference (SMD) and 95\% confidence interval (CI). If studies included more than 1 intervention group, such as different doses of magnesium sulfate, we combine groups to create a single pair-wise comparison based on the recommended of Cochrane handbook [12]. Dichotomous outcomes (postoperative adverse events), the relative ratio (RR) and 95\% $\mathrm{Cl}$ were used as effect indicators. We exclude studies from the meta-analysis where there are no events in both arms according to the Cochrane handbook [12]. Considering the substantial clinical and methodological heterogeneity, we used the randomized effect model [13]. If the $95 \% \mathrm{Cl}$ did not include equivalent line and a P-value $<0.05$, we assumed there was a statistically difference between magnesium sulfate and control group. Publication bias of primary outcome was evaluated by a funnel plot if more than 10 studies had been included. We performed the following sensitivity analysis to assess the stability of primary outcome: (1) excluding studies at 'low' quality; (2) using fixed effect model.

The heterogeneity between studies were measured with the $\mathrm{Chi}^{2}$ test and by calculating the $\mathrm{I}^{2}$ statistic. Substantial heterogeneity was present as $\mathrm{I}^{2}$ greater than $50 \%$. We performed a subgroup analysis when there were sufficient RCTs which reported the duration of analgesia. According to the type of surgery and dose of magnesium sulfate, we conducted a subgroup analysis of cesarean section versus non-cesarean section and low-dose $(\leq 50 \mathrm{mg})$ versus high-dose (>50 mg) magnesium sulfate to explore clinical heterogeneity.

\section{Results}




\subsection{Results of search}

We screened 9,822 possible studies from database searches, then we carried out full-text review of 40 articles after screening based on titles and abstracts. No eligible studies were included by manual retrieval. As a result, 18 studies that met our inclusion criteria were included in our analysis, and the details of study retrieval is shown in Figure 1.

\subsection{Characteristics of the included studies}

The characteristics of the studies are summarized in table 1. Six of the included studies involved cesarean section [14-19], whereas the remaining thirteen involved surgeries in infraumbilical [20,21]; gynaecological [22, 23]; urologic [24]; and orthopaedic [25-31]. Sample sizes ranged from 50 to 150 patients. The mean age of all the participants wass below 50 years old and American Society of Anesthesiologists Physical Status (ASA ) I to II. The doses of magnesium sulfate administrated ranged from 25 to $100 \mathrm{mg}$. All of the eighteen included studies were RCTs conducted in India [20, 21, 23, 26, 27, 29, 31]; Turkey [19]; Egypt [14, 22, 24, 25]; and Iran [15-18, 28, 30]. Four studies were identified as being of 'high' quality according to our predesign criteria [14, 16, 23, 24], leaving 14 low-quality studies. Figure 2 and Figure 3 show the risks of bias in the included studies.

\subsection{Primary outcome}

Fourteen studies reported duration of analgesia ( the time to the first complaint of pain or request for analgesics) [14-16, 19-23, 25-27, 28, 30, 31], one study where the date was reported as histogram was excluded from the quantitative analysis [26]. Finally, thirteen studies including 513 participants in the magnesium sulfate group and 411 participants in the control group were included in the quantitative analysis, and the result demonstrated that the addition of intrathecal magnesium sulfate to bupivacaine provided a longer duration of analgesia compared with the control group (SMD 0.99; $95 \% \mathrm{Cl}[0.45,1.52], \mathrm{P}$ $=0.0003, I^{2}=93 \%$; Figure 4).

Substantial heterogeneity was identified in study effects $\left(1^{2}=93 \%\right)$, we conducted subgroup analysis according to the type of surgery (cesarean section versus non-casarean section) to identify the source of heterogeneity, and still found significant heterogeneity in the cesarean section subgroup $\left(I^{2}=94 \%\right)$ or the non-casarean section subgroup $\left(I^{2}=93 \%\right)$. We also performed the subgroup analysis according to the doses of magnesium sulfate administrated, heterogeneity still existed in the low dose (magnesium sulfate $50 \mathrm{mg}$ ) subgroup $\left(I^{2}=93 \%\right)$ and the high dose (magnesium sulfate $100 \mathrm{mg}$ ) subgroup $\left(I^{2}=84 \%\right)$.

Considering that the number of 'high' quality studies was small and only three [14, 26, 23], we did not conduct a sensitivity analysis based on the quality of studies. we used a fixed effect model which did not alter interpretation of the result.

we performed publication bias analysis using a funnel plot, and found that the funnel plot was symmetrical, indicating less risk of publication bias (Figure 5). 
We used the GRADE approach to judge the quality of the evidence for duration of analgesia to be very low. We downgraded quality due to unclear risk of bias for several key domains among the included studies; the sample sizes of included studies were small; in addition, there was unexplained heterogeneity among studies and imprecision of results (wide confidence intervals).

\subsection{Secondary outcomes}

\subsubsection{The onset and duration of sensory block}

Twelve studies reported the onset of sensory block $[14,16,17,19,22,23,24,26,28-31]$, one study where the date was reported as histogram was excluded from the quantitative analysis [26]. The combined statistical results showed that the time of onset of sensory block was delayed in the magnesium sulfate group compared with the control group (SMD 1.20; 95\% Cl [0.65, 1.75], $\mathrm{P}=<0.0001, \mathrm{I}^{2}=91 \%$; Figure 6).

Twelve studies reported the duration of sensory block [14, 16, 17-19, 23, 24, 26-30]. We excluded one study from the quantitative analysis because the date was reported as histogram [26]. The meta-analysis showed that the duration of sensory block were significantly prolonged in the magnesium sulfate group compared with the control group (SMD 0.59; $95 \% \mathrm{Cl}[0.14,1.04], \mathrm{P}=0.01, \mathrm{I}^{2}=89 \%$; Figure 7).

\subsubsection{The onset and duration of motor block}

Seven studies analysed the onset of motor block $[16,19,23,24,36,28,29]$, In one study date was reported as histogram [26], we excluded it and conducted a meta-analysis showing that there was a significant delay in onset of motor block in the magnesium sulfate group compared with the control group (SMD 1.46; 95\% Cl [0.23, 2.69], $\mathrm{P}=0.02, \mathrm{I}^{2}=96 \%$; Figure 8 ).

Twelve studies reported the duration of motor block [16, 18-21, 23, 24, 26-30], one study where the date was reported as histogram was excluded from the quantitative analysis [26]. The pooled SMD found no significant difference in the duration of motor block between groups (SMD 0.42; $95 \% \mathrm{Cl}[-0.05,0.89], \mathrm{P}$ $=0.08, I^{2}=90 \%$; Figure 9).

\subsubsection{Rescue analgesics consumption}

Rescue analgesics consumption was reported by six studies [22, 23, 25, 26, 28, 30]. We excuded one study from the quantitative analysis because the date was reported as histogram [26]. The combined 
statistical results showed that the rescue analgesics consumption was reduced in magnesium sulfate group compared with the control group (SMD $-0.81 ; 95 \% \mathrm{Cl}[-1.06,-0.56], \mathrm{P}<0.00001, \mathrm{I}^{2}=11 \%$, Figure 10 ).

\subsubsection{Adverse events}

There was no significant difference with regard to hypotension, assessed in seven studies $[18,19,23,24$, $27,28,31]$; bradycardia, reported in five trials [ 19, 23, 24, 28, 31]; nausea and vomiting, reported in eleven trials $[15,16,18,19,22-25,27,30,31]$; pruritus, reported in two trials [19,30]; shivering, reported in seven trials $[17-19,23-25,27]$. There are six studies reported the neurological deficit $[16,18,19,23,27,29]$, all of them observed no neurological deficits in both magnesium and control group.

\section{Discussion}

This meta-analysis aimed to assess the effects and safety of intrathecal magnesium sulfate combined with bupivacaine in adults using spinal anaesthesia. We found that the addition of intrathecal magnesium sulfate to bupivacaine provided a longer duration of analgesia, delayed the onset of sensory and motor block, prolonged the duration of sensory block, reduced postoperative analgesics consumption without significant effects on the adverse effects.

Although we included adults undergoing surgical procedures under spinal anesthesia, all participants in the included studies were less than 60 years old and classed as ASA I or II; therefore, evidence related to the effects and safety of intrathecal magnesium sulfate combined with bupivacaine in the elderly (> 60 years old) or ASA III is still lacking, which may reduce the overall applicability of the evidence.

When assessing the quality of primary outcome (duration of analgesia) using GRADE, we ranked the quality of the evidence as 'very low'. 'Very low quality' means that the estimate of effect is very uncertain, and the true effect may be substantially different from the estimate of the effect. We downgraded by one level for study limitations; on the one hand, many individual trials had unclear risk of bias for domains such as random sequence generation, outcome assessment blinding, and selective reporting; on the other hand, the sample sizes of included studies were small (all the studies included in this meta-analysis had fewer than 50 participants in each group), and small numbers of small studies might have a positive bias in favour of a therapy. We downgraded by two level for substantial heterogeneity and imprecision of results; the differences in the types of surgery performed and the dose of magnesium sulfate administrated might be the source of substantial heterogeneity; however, we found no descent in the degree of heterogeneity among studies when we conducted the subgroup analyses of cesarean section versus non-casarean section and low-dose (magnesium sulfate $50 \mathrm{mg}$ ) versus high-dose (magnesium sulfate $100 \mathrm{mg}$ ); this meta-analysis included a large number of small studies, which probably contributed to the high degree of heterogeneity [32]. 
The review by Pascual-Ramirez $\mathrm{J}$, et al. examined the efficacy and safety of intrathecal magnesium as analgesic adjuvant to local anesthetic and/or opiate, supporting the findings of our review [33]. They found similar results for efficacy, including longer duration of analgesia, delayed the onset of sensory block and no difference in "time to full motor recovery" , incidence of prpostoperative nausea and vomiting, pruritus, bradicardia when intrathecal magnesium was included in the intervention. Unlike our study, the majority of included studies in their reviews administrated magnesium as analgesic adjuvant to local anesthetic and opiate. A review of intrathecal magnesium in the presence or absence of local anaesthetic with and without lipophilic opioids revealed that the duration of spinal anaesthesia (the time from intrathecal injection to the onset of pain) was significantly increased in the experimental group and side effects were similar in both groups [34]. They found are similar to our findings. In contrast to our findings, Morrison AP, ei al. did not observe a delay in the onset of sensory or motor block [34]. Different inclusion criteria may explain the discrepancy with our result; the majority of included studies in their reviews administrated magnesium as analgesic adjuvant to local anesthetic with either intrathecal fentanyl or sufentanil. Some studies suggested that the differences in baricity and $\mathrm{PH}$ of the solution involving magnesium sulfate might contributed to the delayed onset [35]. Wang SC, et al. conducted a meta-analysis of neuraxial magnesium sulfate for postoperative analgesia in cesarean section delivery women [36], assessing similar outcomes to our review.

Although six included studies reported the risk of neurotoxicity with intrathecal magnesium sulfate, none of them have reported any evidence of neurological deficit or other deleterious effects $[16,18,19,23,27$, 29]. Considering the small size of studies in our review, the limited data prevented us from interpreting safety data of intrathecal magnesium sulfate in particular with any confidence. One report described an accidental intrathecal injection of $1000 \mathrm{mg}$ of magnesium induced a transient motor block followed by a complete recovery and no neurological deficit at long-term follow-up [37]. In addition, some animal studies showed no neurotoxicity after repeated intrathecal administration of magnesium sulfate in rats [38]. However, Saeki $\mathrm{H}$, et al. found that intrathecal magnesium $1 \mathrm{mg} / \mathrm{kg}$ has a risk of neurotoxicity in rabbits [39]. Therefore, the safety of intrathecal magnesium sulfate needs to be confirmed by high-quality large sample study.

This meta-analysis does have some limitations. Firstly, the main limitation of the meta-analysis was limited number of patients in the included studies, so it was at bias in favour of treatment effects and underestimating adverse effects. Secondly, data combination was hampered by substantial heterogeneity; although several subgroup analyses were conducted, no exact source for the substantial heterogeneity was found. Thirdly, the GRADE level for duration of analgesia was very low quality advising caution for the conclusions.

\section{Conclusion}

In conclusion, Our meta-analysis demonstrated that intrathecal magnesium sulfate combined with bupivacaine prolongs the dusration of analgesia, without an impact on the adverse events. However, the quality of evidence was very low when using GRADE to assess it. Given adverse effects before use, 
more high-quality trials with large samples are required before magnesium sulfate is routinely used as a intrathecal adjunct.

\section{Abbreviations}

NMDA: N-methyl-D-aspartate, PRISMA: Preferred Reporting Items for Systematic Reviews and MetaAnalyses, RCTs: randomized controlled trials, PONV: postoperative nausea and vomiting, SD: standard deviation, IQRs: interquartile ranges, SMD: standardized mean difference, Cl: confidence intervals, RR: relative risk.

\section{Declarations}

\section{Acknowledgements}

Not applicable.

\section{Funding}

There was no funding source in this study.

\section{Availability of data and material}

All data generated or analysed during this study are included in this published article.

\section{Authors' contributions}

WZM was involved in the design. WZM, DR and JLN participated in collecting the data, performing the quality assessment. ZJH participated in the study design and drafting the manuscript. ADB, JLN, DR helped to perform statistical analyses and conduct search strategy. All authors read and approved the final manuscript.

\section{Ethics approval and consent to participate}

Not applicable. 


\section{Consent for publication}

Not applicable.

\section{Competing interests}

The authors declare that they have no competing interests.

\section{References}

1. Apfelbaum JL, Chen C, Mehta SS, et al. Postoperative pain experience: results from a national survey suggest postoperative pain continues to be undermanaged. Anesth Analg. 2003;97(2):534-40.

2. Gan TJ, Habib AS, Miller TE, et al. Incidence, patient satisfaction, and perceptions of post-surgical pain: results from a US national survey. Curr Med Res Opin. 2014;30(1):149-60.

3. Kehlet H, Jensen TS, Woolf CJ. Persistent postsurgical pain: risk factors and prevention. Lancet. 2006;367(9522):1618-25.

4. Ali MA, Ismail S, Sohaib M, et al. A double-blind randomized control trial to compare the effect of varying doses of intrathecal fentanyl on clinical efficacy and side effects in parturients undergoing cesarean section. J Anaesthesiol Clin Pharmacol. 2018;34(2):221-6.

5. Routray SS, Raut K, Pradhan A, et al. Comparison of Intrathecal Clonidine and Fentanyl as Adjuvant to Hyperbaric Bupivacaine in Subarachnoid Block for Lower Limb Orthopedic Surgery. Anesth Essays Res. 2017;11(3):589-93.

6. Karbasfrushan A, Farhadi K, Amini-Saman J, et al. Effect of intrathecal midazolam in the severity of pain in cesarean section: a randomized controlled trail. Iran Red Crescent Med J. 2012;14(5):276-82.

7. Woolf CJ, Thompson SW. The induction and maintenance of central sensitization is dependent on $\mathrm{N}$ methyl-D-aspartic acid receptor activation; implications for the treatment of post-injury pain hypersensitivity states. Pain. 1991;44(3):293-9.

8. Mayer ML, Westbrook GL, Guthrie PB. Voltage-dependent block by Mg2+ of NMDA responses in spinal cord neurones. Nature. 1984; 309(5965):261-3.

9. Liberati A, Altman DG, Tetzlaff J, et al. The PRISMA statement for reporting systematic reviews and meta-analyses of studies that evaluate healthcare interventions: explanation and elaboration. BMJ. 2009;339:b2700.

10. Guyatt GH, Oxman AD, Vist GE, et al. GRADE: an emerging consensus on rating quality of evidence and strength of recommendations. BMJ.2008;336(7650):924-6. 
11. Wan X, Wang W, Liu J, Tong T. 2014. Estimating the sample mean and standard deviation from the sample size, median, range and/or interquartile range. BMC Med Res Methodol. 14:135.

12. Higgins JPT, Green S (editors). Cochrane Handbook for Systematic Reviews of Interventions Version 5.1.0 [updated March 2011]. The Cochrane Collaboration. 2011. Available from http://www.cochranehandbook.org. Nature. 1984;309(5965):261-3.

13. Shuster JJ, Walker MA. Low-event-rate meta-analyses of clinical trials: implementing good practices. Stat Med. 2016;35(14):2467-78.

14. 14. Mostafa MF, Herdan R, Fathy GM, et al. Intrathecal dexmedetomidine versus magnesium sulphate for postoperative analgesia and stress response after caesarean delivery; randomized controlled double-blind study. Eur J Pain. 2020;24(1):182-91.

15. 15. Zakeri $H$, Pouralborz $Y$, Askari A, et al. The adjunctive midazolam or magnesium sulfate to intrathecal bupivacaine analgesic effect in caesarean section: A randomized controlled trial. Biomedical Research (India). 2017;28(8):3783-7.

16. 16. Banihashem N, Hasannasab B, Esmaeili A, et al. Addition of Intrathecal Magnesium Sulfate to Bupivacaine for Spinal Anesthesia in Cesarean Section. Anesth Pain Med. 2015;5(3):e22798.

17. 17. Faiz SHR, Rahimzadeh $P$, Imani F, et al. Intrathecal injection of magnesium sulfate: Shivering prevention during cesarean section: A randomized, double-blinded, controlled study. Korean Journal of Anesthesiology. 2013;65(4):293-8.

18. 18. Jabalameli M, Pakzadmoghadam SH. Adding different doses of intrathecal magnesium sulfate for spinal anesthesia in the cesarean section: A prospective double blind randomized trial. Adv Biomed Res. 2012;1:7.

19. 19. Unlugenc $H$, Ozalevli $M$, Gunduz $M$, et al. Comparison of intrathecal magnesium, fentanyl, or placebo combined with bupivacaine $0.5 \%$ for parturients undergoing elective cesarean delivery. Acta Anaesthesiol Scand. 2009;53(3):346-53.

20. 20. Yadav $M$, Kumar PB, Singh $M$, et al. Intrathecal magnesium sulfate as a spinal adjuvant in two different doses, combined with $0.5 \%$ heavy bupivacaine for infraumbilical surgeries. Anesth Essays Res. 2015;9(3):364-8.

21. 21. Katiyar S, Dwivedi C, Tipu S, et al. Comparison of different doses of magnesium sulphate and fentanyl as adjuvants to bupivacaine for infraumbilical surgeries under subarachnoid block. Indian $\mathrm{J}$ Anaesth. 2015;59(8):471-5.

22. 22. Mohamed KS, Abd-Elshafy SK, El Saman AM. The impact of magnesium sulfate as adjuvant to intrathecal bupivacaine on intra-operative surgeon satisfaction and postoperative analgesia during laparoscopic gynecological surgery: randomized clinical study. Korean J Pain. 2017;30(3):207-13.

23. 23. Joshi-Khadke S, Khadke VV, Patel SJ, et al. Efficacy of spinal additives neostigmine and magnesium sulfate on characteristics of subarachnoid block, hemodynamic stability and postoperative pain relief: A randomized clinical trial. Anesth Essays Res. 2015;9(1):63-71.

24. 24. Omar H, Aboella WA, Hassan MM, et al. Comparative study between intrathecal dexmedetomidine and intrathecal magnesium sulfate for the prevention of post-spinal anaesthesia 
shivering in uroscopic surgery; (RCT). BMC Anesthesiol. 2019;19(1):190.

25. 25. El Sayed M, Hassan S. Different routes of co-administration of magnesium sulphate with spinal anesthesia in knee arthroscopy: Randomized controlled trial. Egyptian Journal of Anaesthesia. 2019;33(3):271-6.

26. 26. Kathuria B, Luthra N, Gupta A, et al. Comparative efficacy of two different dosages of intrathecal magnesium sulphate supplementation in subarachnoid block. J Clin Diagn Res. 2014;8(6):Gc01-5.

27. 27. Jaiswal R, Bansal T, Kothari S. The effect of adding magnesium sulphate to bupivacaine for spinal anaesthesia: A randomised, double- blind trial in patients undergoing lower limb orthopaedic surgery. International Journal of Pharmacy and Pharmaceutical Sciences. 2013;5(4):179-82.

28. 28. Khezri MB, Yaghobi S, Hajikhani M, et al. Comparison of postoperative analgesic effect of intrathecal magnesium and fentanyl added to bupivacaine in patients undergoing lower limb orthopedic surgery. Acta Anaesthesiol Taiwan. 2012;50(1):19-24.

29. 29. Shukla D, Verma A, Agarwal A, et al. Comparative study of intrathecal dexmedetomidine with intrathecal magnesium sulfate used as adjuvants to bupivacaine. J Anaesthesiol Clin Pharmacol. 2011;27(4):495-9.

30. 30. Khalili G, Janghorbani M, Sajedi P, et al. Effects of adjunct intrathecal magnesium sulfate to bupivacaine for spinal anesthesia: a randomized, double-blind trial in patients undergoing lower extremity surgery. J Anesth. 2011;25(6):892-7.

31. 31. Paul S, Bhattactarjee DP, Ghosh S, et al. Efficacy and safety of intrathecal magnesium sulphate as an adjunct to bupivacaine for lower limb orthopaeadic surgery. Pharmacologyonline. 2009;2:5704.

32. 32. Gavaghan DJ, Moore RA, McQuay HJ. An evaluation of homogeneity tests in meta-analyses in pain using simulations of individual patient data. Pain. 2000;85(3):415-24.

33. 33. Pascual-Ramirez J, Gil-Trujillo S, Alcantarilla C. Intrathecal magnesium as analgesic adjuvant for spinal anesthesia: a meta-analysis of randomized trials. Minerva Anestesiol. 2013;79(6):667-78.

34. 34. Morrison AP, Hunter JM, Halpern SH, et al. Effect of intrathecal magnesium in the presence or absence of local anaesthetic with and without lipophilic opioids: a systematic review and metaanalysis. Br J Anaesth. 2013;110(5):702-12.

35. 35. Buvanendran A, McCarthy RJ, Kroin JS, et al. Intrathecal magnesium prolongs fentanyl analgesia: a prospective, randomized, controlled trial. Anesth Analg. 2002;95(3):661-6, table of contents.

36. 36. Wang SC, Pan PT, Chiu HY, et al. Neuraxial magnesium sulfate improves postoperative analgesia in Cesarean section delivery women: A meta-analysis of randomized controlled trials. Asian $\mathrm{J}$ Anesthesiol. 2017;55(3):56-67.

37. 37. Lejuste MJ. Inadvertant intrathecal administration of magnesium sulfate. S Afr Med J. 1985;68(6):367-8.

38. 38. Chanimov M, Cohen ML, Grinspun Y, et al. Neurotoxicity after spinal anaesthesia induced by serial intrathecal injections of magnesium sulphate. An experimental study in a rat model. 
Anaesthesia. 1997;52(3):223-8.

39. 39. Saeki H, Matsumoto M, Kaneko S, et al. Is intrathecal magnesium sulfate safe and protective against ischemic spinal cord injury in rabbits? Anesth Analg. 2004;99(6):1805-12, table of contents.

\section{Table 1}

Table 1 Characteristics of included trials

NR: not report; N/S: nomal saline ; MgSO4: magnesium sulfate; IM: intramuscular; VAS: visual analogue scale scores; VRS:verbal rating scale; SD:standard deviation.

Figures 


\begin{tabular}{|c|c|c|c|c|c|c|c|c|}
\hline Study ID & $\begin{array}{l}\text { Patients } \\
\left(\mathrm{MgSO}_{4} / \text { control }\right)\end{array}$ & $\begin{array}{l}\text { Age } \\
\left(\mathrm{MgSO}_{4} / \text { control }\right)\end{array}$ & ASA & Type of Surgery & $\begin{array}{l}\text { Spinal } \\
\text { bupivacaine } \\
\text { dose }\end{array}$ & $\begin{array}{l}\mathrm{MgSO}_{4} \\
\text { dose }\end{array}$ & Control & $\begin{array}{l}\text { Postoperative } \\
\text { analgesia regimen }\end{array}$ \\
\hline
\end{tabular}

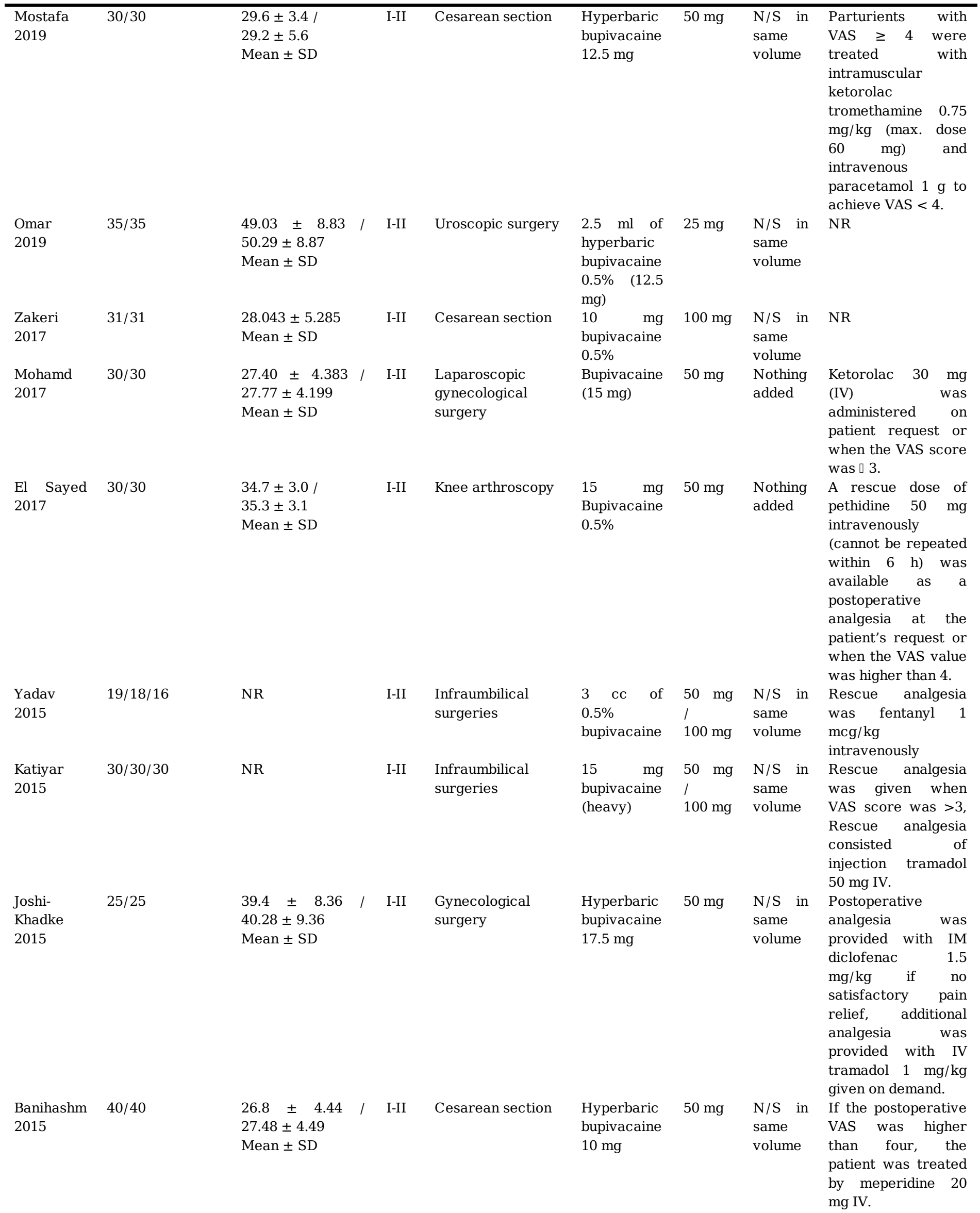




\begin{tabular}{|c|c|c|c|c|c|c|c|c|}
\hline $\begin{array}{l}\text { Kathuria } \\
2014\end{array}$ & $30 / 30 / 30$ & $\begin{array}{l}\text { MgSO4 (50mg): } \\
36.4 \\
\text { MgSO4 (75mg): } \\
43.1 / \\
\text { Control : } \\
\text { Mean }\end{array}$ & I-II & $\begin{array}{l}\text { Orthopaedic lower } \\
\text { limb surgery }\end{array}$ & $\begin{array}{l}\text { Bupivacaine } \\
(0.5 \%), 12.5 \\
\mathrm{mg}\end{array}$ & $\begin{array}{l}50 \mathrm{mg} \\
/ \\
75 \mathrm{mg}\end{array}$ & $\begin{array}{l}\mathrm{N} / \mathrm{S} \text { in } \\
\text { same } \\
\text { volume }\end{array}$ & $\begin{array}{l}\text { Any patient showing } \\
\text { VAS more than or } \\
\text { equal to } 3 \text { was } \\
\text { administered a } \\
\text { supplemental dose } \\
\text { of an analgesic with } \\
\text { Inj. Tramadol } \\
1 \mathrm{mg} / \mathrm{kg} \\
\text { intravenously and } \\
\text { was quantified and } \\
\text { documented in all } \\
\text { the groups. }\end{array}$ \\
\hline $\begin{array}{l}\text { Jaiswal } \\
2013\end{array}$ & $50 / 50 / 50$ & $\begin{array}{l}\text { MgSO4 (50mg): } \\
37.08 \pm 13.70 \\
\text { MgSO4 (100mg): } \\
35.50 \pm 12.29 / \\
\text { Control : } \\
37.10 \pm 12.09 \\
\text { Mean } \pm \text { SD }\end{array}$ & I-II & $\begin{array}{ll}\text { Lower } & \text { limb } \\
\text { orthopaedic } & \\
\text { surgery } & \end{array}$ & $\begin{array}{l}2.5 \mathrm{ml} \text { of } \\
0.5 \% \\
\text { bupivacaine } \\
\text { heavy }\end{array}$ & $\begin{array}{l}50 \mathrm{mg} \\
/ \\
100 \mathrm{mg}\end{array}$ & $\begin{array}{l}\mathrm{N} / \mathrm{S} \text { in } \\
\text { same } \\
\text { volume }\end{array}$ & $\begin{array}{l}\text { When VAS was } \\
\text { equal to } 4 \text {, all the } \\
\text { patients received } \\
\text { diclofenac } 75 \mathrm{mg} \text { IM } \\
\text { as analgesia and the } \\
\text { time was recorded. }\end{array}$ \\
\hline Faiz 2013 & $36 / 36$ & $\begin{array}{l}26.22 \pm 3.78 \\
27.20 \pm 3.94 \\
\text { Mean } \pm \text { SD }\end{array}$ & I-II & Cesarean section & $\begin{array}{l}2 \mathrm{ml} \text { of } \\
0.5 \% \\
\text { bupivacaine }\end{array}$ & $25 \mathrm{mg}$ & $\begin{array}{l}\mathrm{N} / \mathrm{S} \text { in } \\
\text { same } \\
\text { volume }\end{array}$ & NR \\
\hline $\begin{array}{l}\text { Khezri } \\
2012\end{array}$ & $30 / 30$ & $\begin{array}{l}42.7 \pm 12.93 \\
42.03 \pm 12.25 \\
\text { Mean } \pm \text { SD }\end{array}$ & I-II & Femur surgery & $\begin{array}{l}15 \quad \mathrm{mg} \\
\text { bupivacaine } \\
(0.5 \% \\
\text { hyperbaric } \\
\text { solution) }\end{array}$ & $\begin{array}{l}0.5 \mathrm{~mL} \\
\text { of } 10 \% \\
\text { MgSO4 }\end{array}$ & $\begin{array}{l}\mathrm{N} / \mathrm{S} \text { in } \\
\text { same } \\
\text { volume }\end{array}$ & $\begin{array}{l}\text { If the VRS exceeded } \\
4 \text { and the patient } \\
\text { requested } \\
\text { supplement } \\
\text { analgesic, } \\
\text { methadone } 5 \text { mg } \\
\text { was given } \\
\text { intravenously. }\end{array}$ \\
\hline $\begin{array}{l}\text { Jabalameli } \\
2012\end{array}$ & $33 / 33 / 33 / 33$ & $\begin{array}{l}\text { MgSO4 (50mg): } 28 \\
\pm \quad 3.6 \quad \mathrm{MgSO} 4 \\
(75 \mathrm{mg}): 26 \pm 4.8 \\
\text { MgSO4(100mg): } 27 \\
\pm 4.8 / \text { Control : } \\
26.7 \pm 3 \\
\text { Mean } \pm \text { SD }\end{array}$ & I-II & Caesarean section & $\begin{array}{l}12.5 \mathrm{mg}(2.5 \\
\mathrm{mL}) \\
\text { hyperbaric } \\
\text { bupivacaine } \\
0.5 \%\end{array}$ & $\begin{array}{l}50 \mathrm{mg} \\
/ \\
75 \mathrm{mg} \\
/ \\
100 \mathrm{mg}\end{array}$ & $\begin{array}{l}\mathrm{N} / \mathrm{S} \text { in } \\
\text { same } \\
\text { volume }\end{array}$ & NR \\
\hline $\begin{array}{l}\text { Shukla } \\
2011\end{array}$ & $30 / 30$ & Shown as figure & I-II & $\begin{array}{l}\text { Lower abdominal } \\
\text { and lower limb } \\
\text { surgery }\end{array}$ & $\begin{array}{l}15 \quad \mathrm{mg} \\
\text { hyperbaric } \\
\text { bupivacaine }\end{array}$ & $50 \mathrm{mg}$ & $\begin{array}{l}\mathrm{N} / \mathrm{S} \text { in } \\
\text { same } \\
\text { volume }\end{array}$ & NR \\
\hline $\begin{array}{l}\text { Khalili } \\
2011\end{array}$ & $40 / 39$ & $\begin{array}{l}36.4 \pm 14.6 / \\
41.3 \pm 16.2 \\
\text { Mean } \pm \text { SD }\end{array}$ & I-II & $\begin{array}{l}\text { Lower extremity } \\
\text { surgery }\end{array}$ & $\begin{array}{l}15 \quad \mathrm{mg} \\
\text { isobaric } \\
\text { bupivacaine } \\
0.5 \%(3 \mathrm{ml})\end{array}$ & $100 \mathrm{mg}$ & $\begin{array}{l}\mathrm{N} / \mathrm{S} \text { in } \\
\text { same } \\
\text { volume }\end{array}$ & $\begin{array}{l}\text { If the VRS exceeded } \\
3 \text {, tramadol } \mathrm{HCl}, 1 \\
\mathrm{mg} / \mathrm{kg} \text {, was given } \\
\text { intravenously for } \\
\text { pain relief. Patients } \\
\text { were allowed to } \\
\text { take tramadol } \\
\text { tablets, } 50 \text { mg every } \\
6 \quad \mathrm{~h} \text { following } \\
\text { surgery, when they } \\
\text { requested } \\
\text { analgesics } \\
\text { subsequent for } \\
\text { relief. }\end{array}$ \\
\hline Paul 2009 & $30 / 30$ & $\begin{array}{l}46.7[35-65] / \\
41.4[35-65] \\
\text { (mean; range) }\end{array}$ & I-II & $\begin{array}{ll}\text { Lower } & \text { limb } \\
\text { orthopaedic } & \\
\text { surgery } & \end{array}$ & $\begin{array}{l}15 \mathrm{mg} \text { of } \\
\text { bupivacaine } \\
\text { (heavy) }\end{array}$ & $50 \mathrm{mg}$ & $\begin{array}{l}\mathrm{N} / \mathrm{S} \text { in } \\
\text { same } \\
\text { volume }\end{array}$ & $\begin{array}{l}\text { Postoperative } \\
\text { rescue analgesia in } \\
\text { the form of } \\
\text { diclofenac sodium } \\
(1.5 \mathrm{mg} / \mathrm{kg}) \\
\text { intramuscular was } \\
\text { given on patient's } \\
\text { demand. }\end{array}$ \\
\hline $\begin{array}{l}\text { Unlugenc } \\
2009\end{array}$ & $30 / 30$ & $\begin{array}{l}36.9(35.9-37.8) / \\
37.3 \\
(36.3-38.3) \\
\text { mean }(95 \% \text { CI })\end{array}$ & I-II & Caesarean section & $\begin{array}{l}10 \mathrm{mg} \text { of } \\
\text { isobaric } \\
\text { bupivacaine } \\
0.5 \%(2 \mathrm{ml})\end{array}$ & $50 \mathrm{mg}$ & $\begin{array}{l}\mathrm{N} / \mathrm{S} \text { in } \\
\text { same } \\
\text { volume }\end{array}$ & $\begin{array}{l}\text { If the VRS exceeded } \\
\text { three or if the } \\
\text { patient requested a } \\
\text { supplement } \\
\text { analgesic, } 20 \mathrm{mg} \text { of } \\
\text { bupivacaine } 0.5 \% \text { ( } 4 \\
\text { ml) plus } 50 \mathrm{mcg} \text { of }\end{array}$ \\
\hline
\end{tabular}


fentanyl (1.0 $\mathrm{ml})$ plus $5 \mathrm{ml}$ saline, as a mixture, was to be given epidurally for post-operative pain relief.

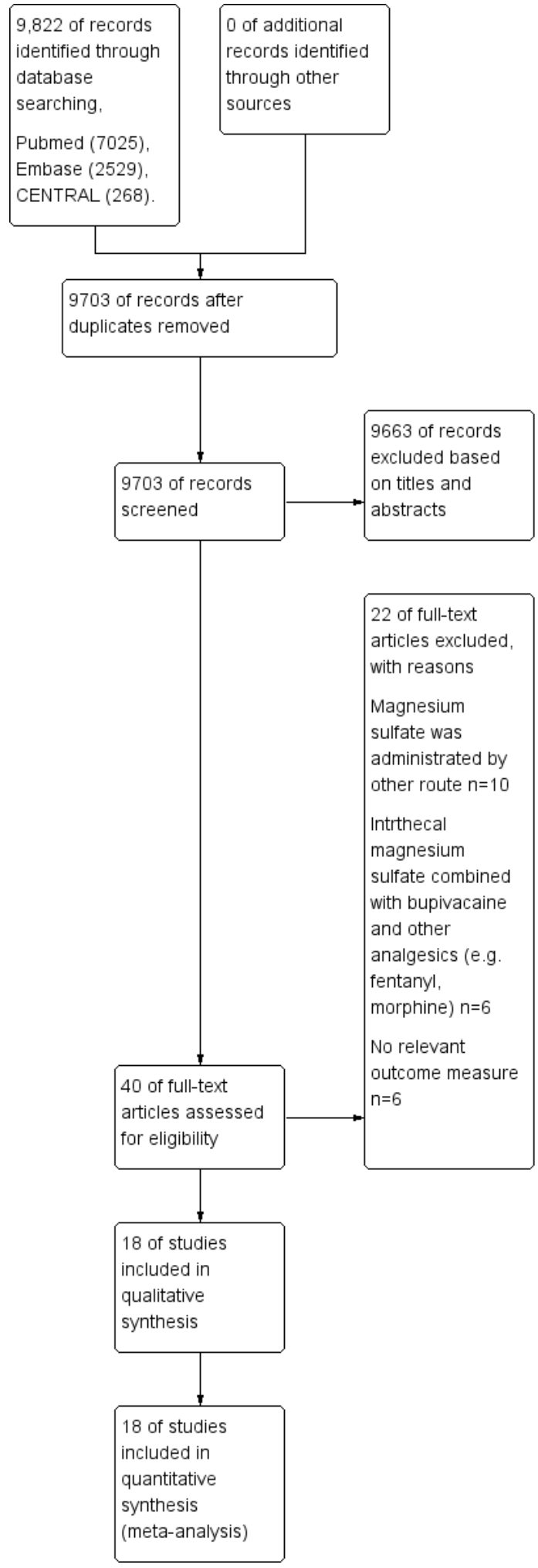

Figure 1

Flow chart of study selection. 


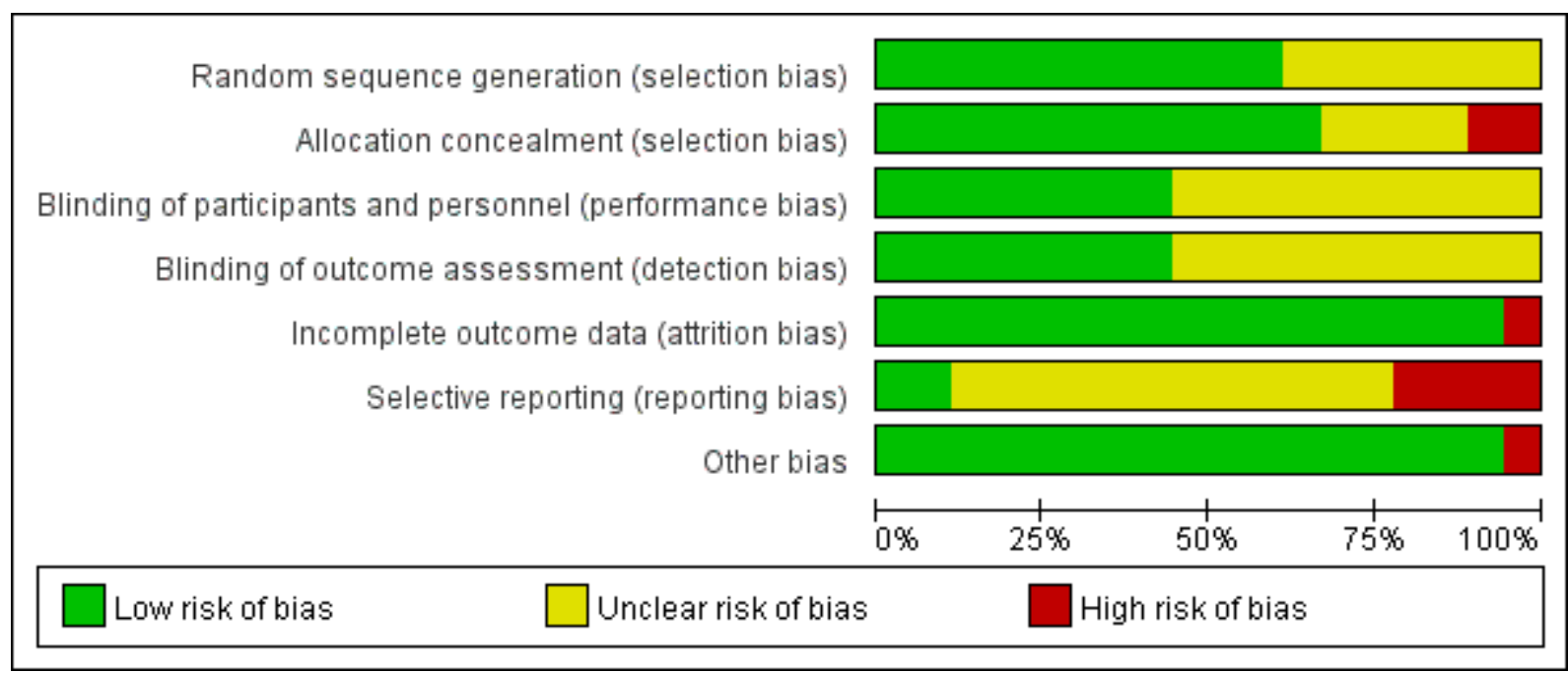

\section{Figure 2}

Risk of bias graph. Review authors' judgements about each risk of bias item presented as percentages across all included studies. 


\begin{tabular}{|c|c|c|c|c|c|c|c|}
\hline & 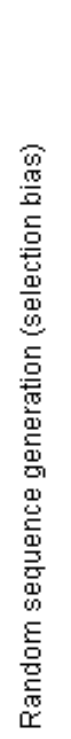 & 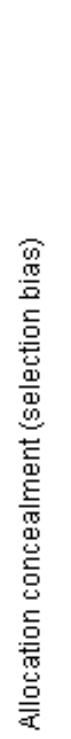 & 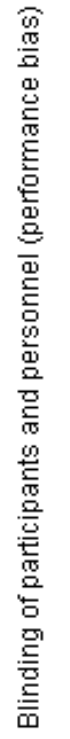 & 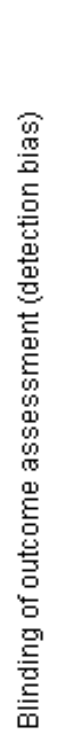 & 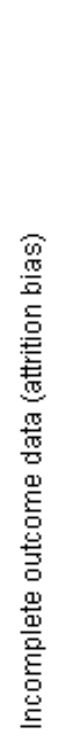 & 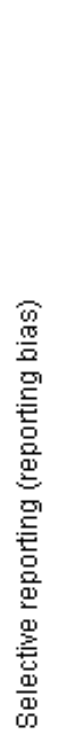 & 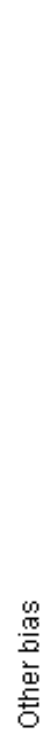 \\
\hline Banihashem 2015 & + & + & + & + & + & $?$ & 0 \\
\hline El Sayed 2017 & + & $\theta$ & $?$ & $?$ & $\odot$ & $?$ & + \\
\hline Faiz 2013 & $?$ & $\odot$ & $?$ & $\odot$ & $\odot$ & $?$ & $\odot$ \\
\hline Jabalameli 2012 & $?$ & $\odot$ & $?$ & $?$ & $\odot$ & $?$ & + \\
\hline Jaiswal 2013 & $?$ & + & 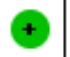 & $\odot$ & 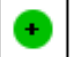 & $?$ & + \\
\hline Joshi-Khadke 2015 & + & + & + & $\odot$ & + & $?$ & + \\
\hline Kathuria 2014 & + & + & $?$ & $\odot$ & + & $?$ & + \\
\hline Katiyar 2015 & $?$ & $\odot$ & + & $?$ & + & $?$ & + \\
\hline Khalili 2011 & $\odot$ & $\odot$ & $\odot$ & $?$ & + & $?$ & + \\
\hline Khezri 2012 & $?$ & $\odot$ & $?$ & $?$ & + & + & $\oplus$ \\
\hline Mohamed 2017 & + & O & $?$ & $?$ & $\odot$ & $\theta$ & $\odot$ \\
\hline Mostafa 2019 & + & $\odot$ & $\odot$ & $\odot$ & + & $\theta$ & $\odot$ \\
\hline Omar 2019 & + & $\odot$ & $\odot$ & $\odot$ & + & $\odot$ & $\odot$ \\
\hline Paul 2009 & $?$ & $?$ & $?$ & $?$ & + & $?$ & + \\
\hline Shukla 2011 & + & $?$ & $?$ & $\odot$ & + & $\theta$ & $\odot$ \\
\hline Unlugenc 2009 & $\odot$ & $\odot$ & $\odot$ & $?$ & $\odot$ & $?$ & $\odot$ \\
\hline Yadav 2015 & $?$ & $?$ & $?$ & $?$ & $\theta$ & $\theta$ & + \\
\hline Zakeri 2017 & + & $?$ & $?$ & $?$ & + & $?$ & + \\
\hline
\end{tabular}

\section{Figure 3}

Risk of bias summary: review authors' judgements about each risk of bias item for each included study. 


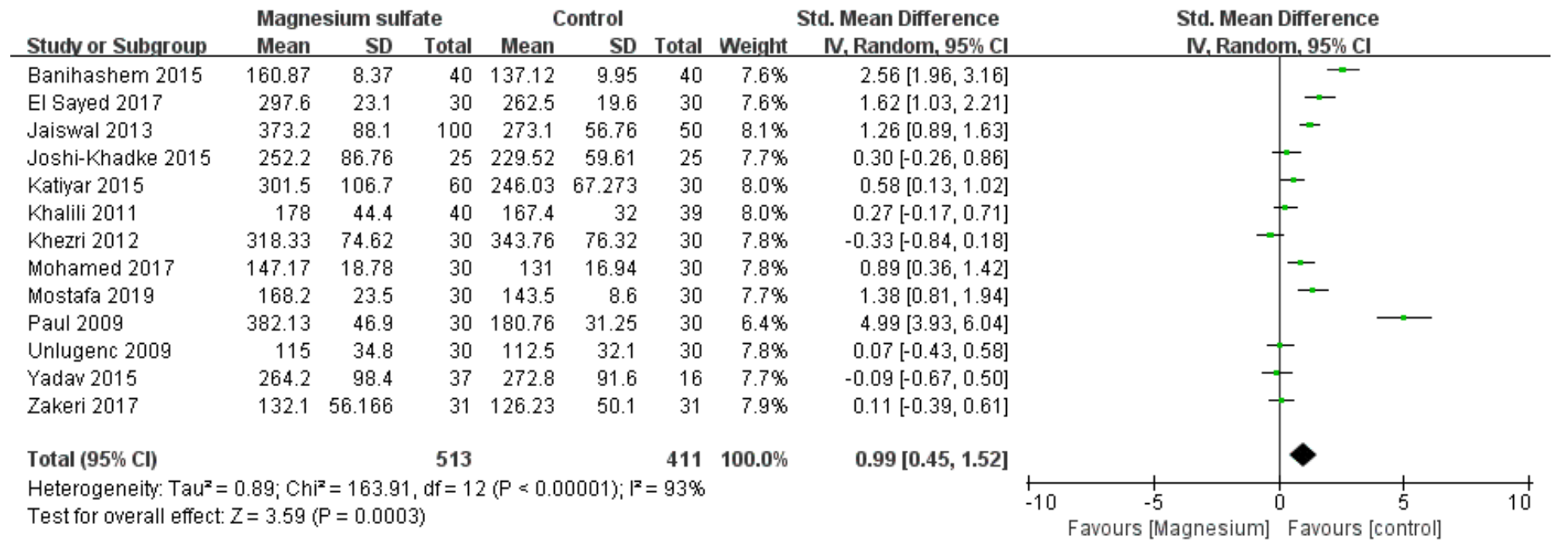

Figure 4

Forest plot of comparison: Magnesium sulfate vs Control, Outcome: the duration of analgesia.

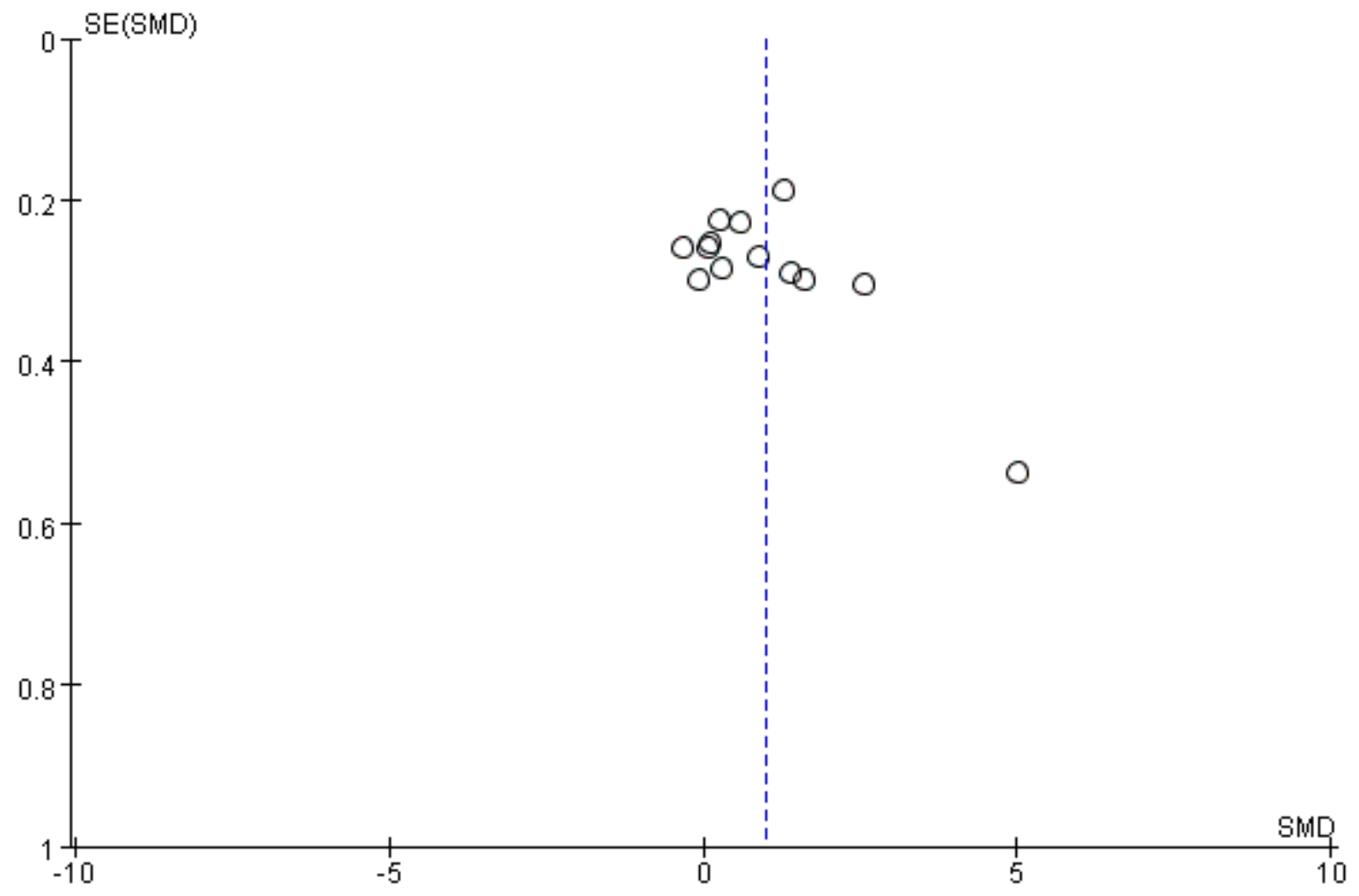

Figure 5

Funnel plot of comparison: Magnesium sulfate vs Control, Outcome: the duration of analgesia. 


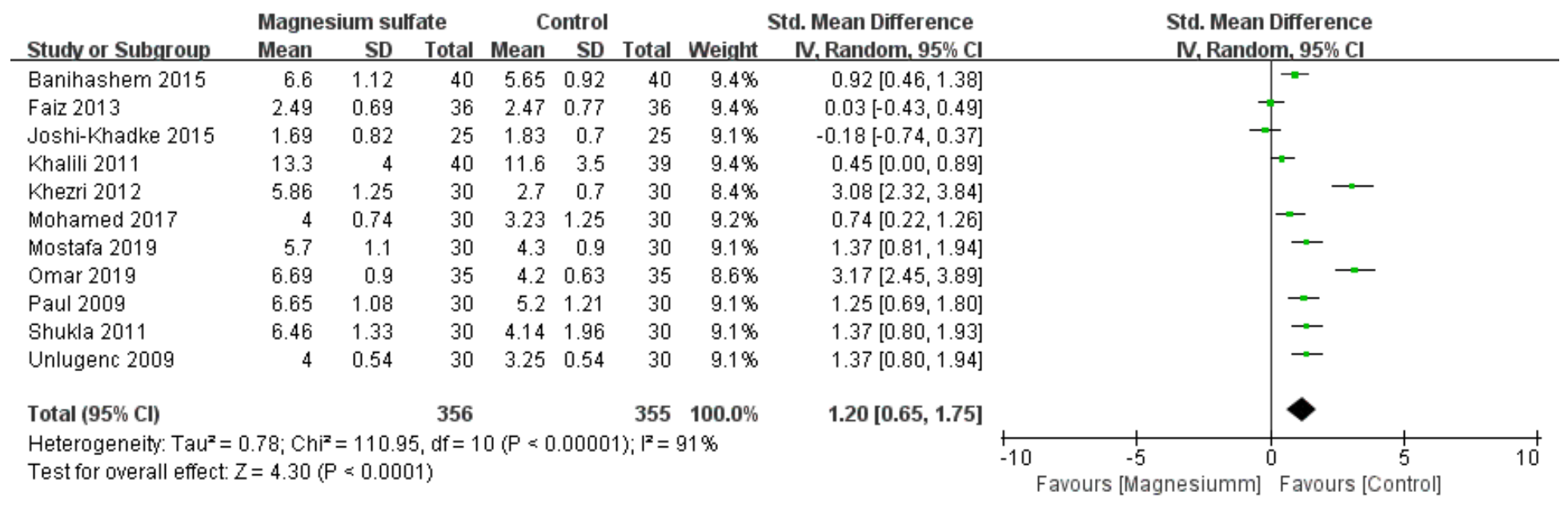

\section{Figure 6}

Forest plot of comparison: Magnesium sulfate vs Control, Outcome: the onset of sensory block.

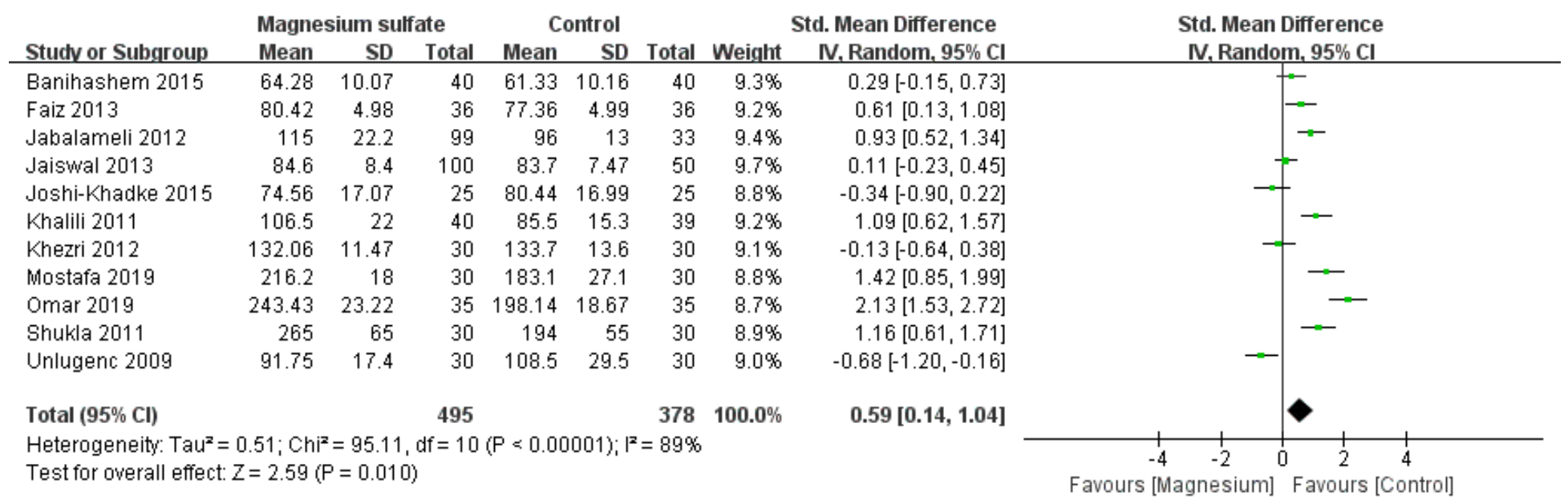

Figure 7

Forest plot of comparison: Magnesium sulfate vs Control, Outcome: the duration of sensory block.

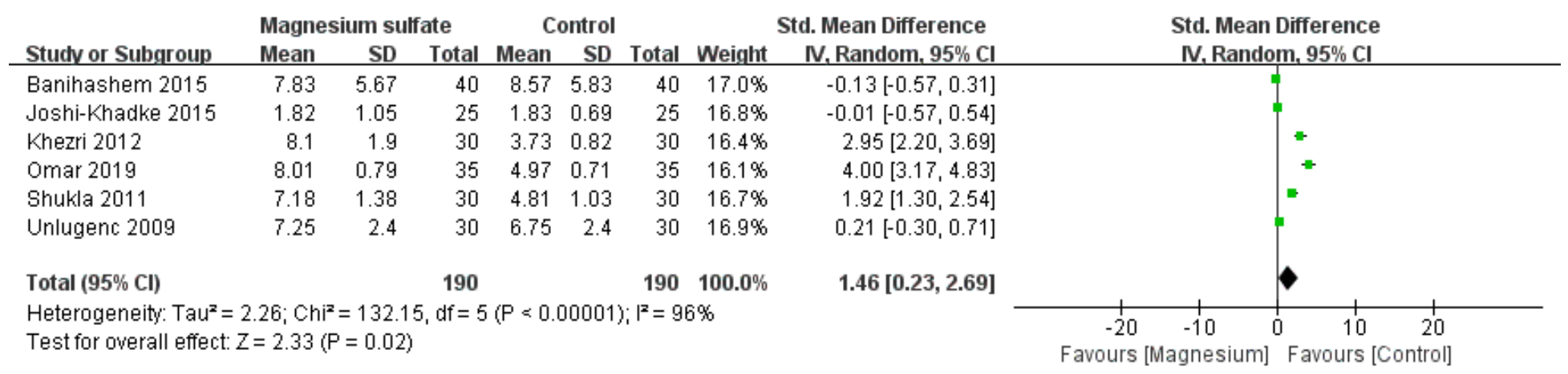

\section{Figure 8}

Forest plot of comparison: Magnesium sulfate vs Control, Outcome: the onset of motor block. 


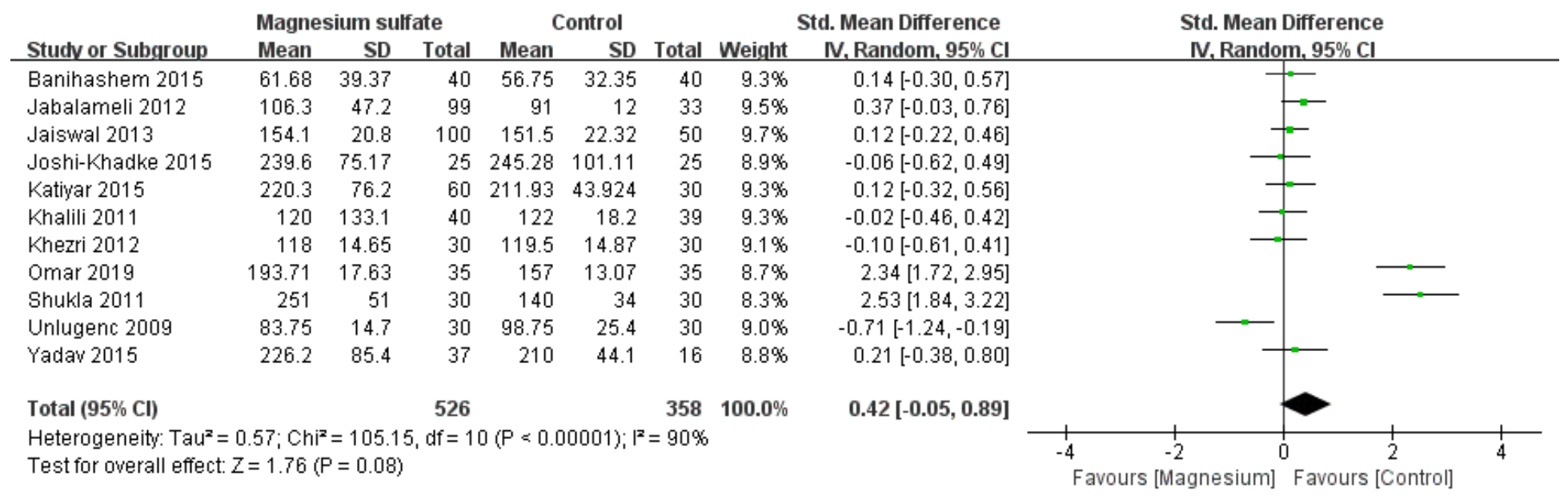

Figure 9

Forest plot of comparison: Magnesium sulfate vs Control, Outcome: the duration of motor block.

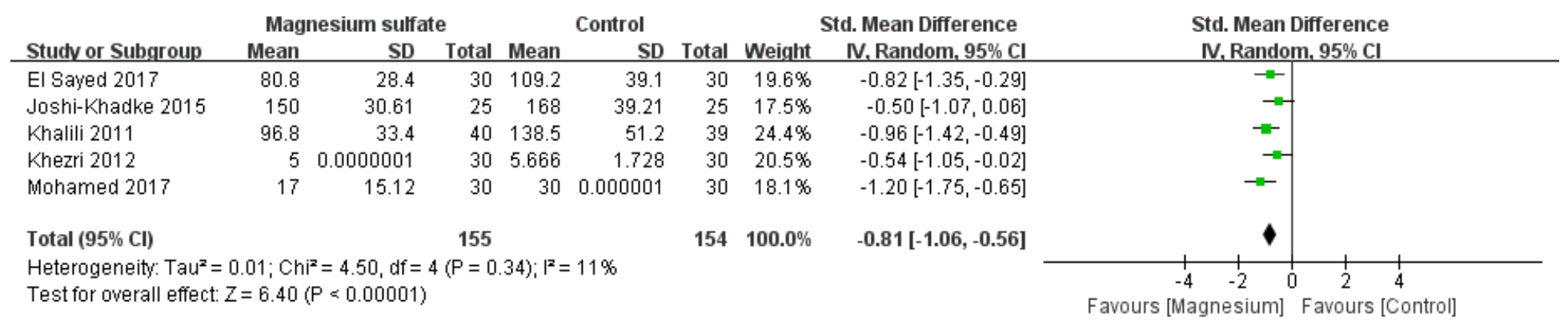

\section{Figure 10}

Forest plot of comparison: Magnesium sulfate vs Control, Outcome: the requirement for rescue analgesics. 
Magnesium sulfate Control

Risk Ratio

Risk Ratio

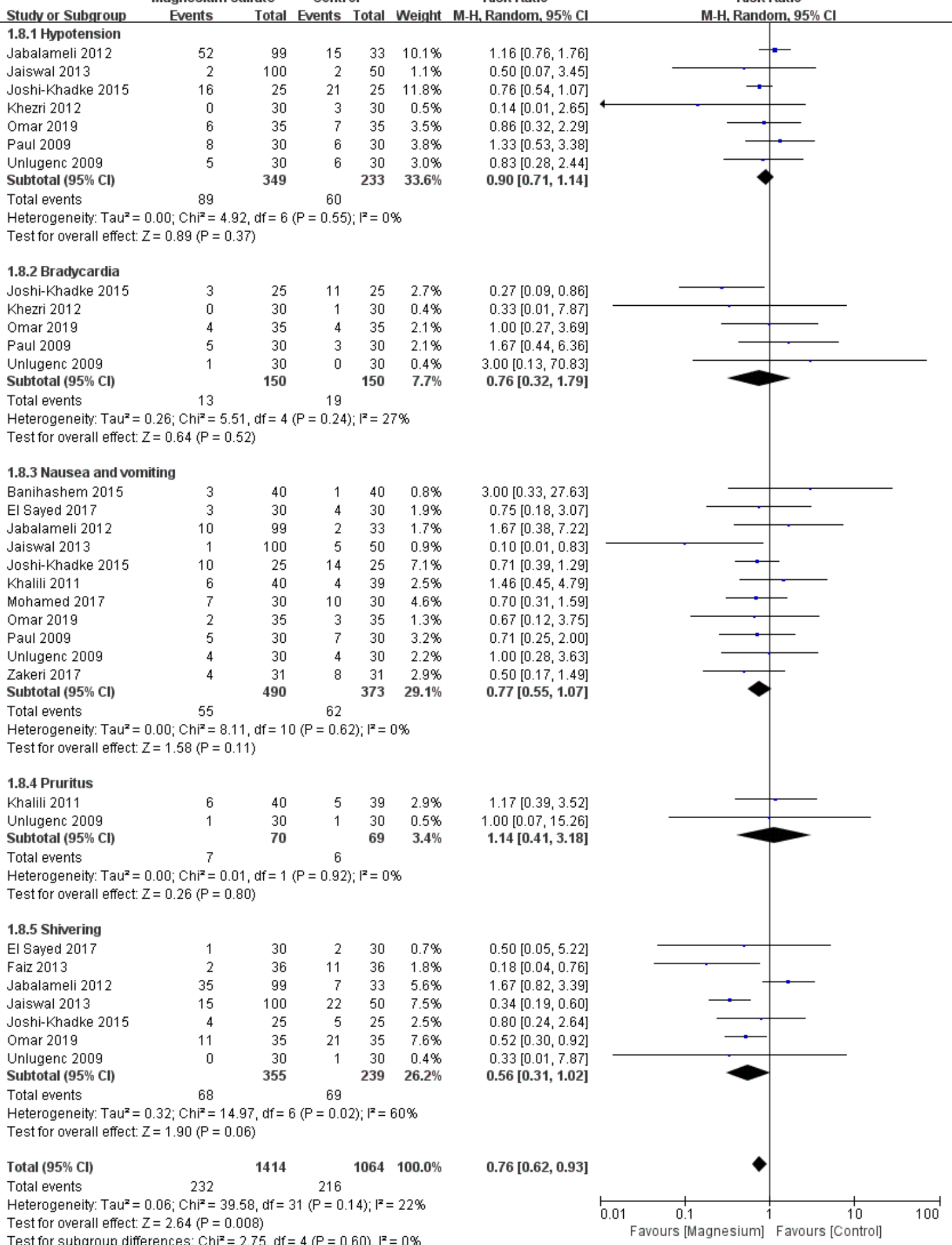

\section{Figure 11}

Forest plot of comparison: Magnesium sulfate vs Control, Outcome: the postoperative adverse events.

\section{Supplementary Files}

This is a list of supplementary files associated with this preprint. Click to download. 
- PRISMAChecklist.doc

Page 23/23 